\title{
Reclassifying by highest complexity operation rather than first operation influences mortality after pediatric heart surgery
}

\author{
Punkaj Gupta, MBBS, ${ }^{\mathrm{a}, \mathrm{b}}$ Mallikarjuna Rettiganti, PhD, ${ }^{\mathrm{b}}$ Takeshi Shinkawa, MD, ${ }^{\mathrm{b}, \mathrm{c}}$ \\ Jeffrey M. Gossett, MS, ${ }^{\text {b,d }}$ Nancy Brundage, BSN, RN, ${ }^{e}$ Howard E. Jeffries, MD, MBA, ${ }^{\mathrm{f}}$ and \\ Rebecca A. Bertrandt, MD $^{g}$
}

\section{ABSTRACT}

Objective: To evaluate the effect on mortality of reclassifying patients undergoing pediatric heart reoperations of varying complexity by operation of highest complexity instead of by first operation.

Methods: Data from the Virtual Pediatric Systems Database on children aged $<18$ years who underwent heart surgery (with or without cardiopulmonary bypass) were included (2009-2015). Only patients who underwent reoperations during the same hospitalization were included. Patients were classified based on the first cardiovascular operation (the index operation), and on the complexity of the operation (the operation with the highest Society of Thoracic SurgeonsEuropean Association for Cardio-Thoracic Surgery [STAT] mortality category of each hospital admission) performed.

Results: Of 51,047 patients (73 centers), 22,393 met inclusion criteria. Using index operation as the classifying operation, the number of patients classified in the STAT 1 category increased by approximately 2.5 times compared with the highest-complexity operation (index, 7,077 and highest complexity, 2,654). In contrast, when the highest-complexity classification was used, we noted an increase in the number of patients in other STAT categories. We also noted higher mortality in all STAT categories when patients were classified by index operation instead of by highest complexity (index vs highest STAT category $1,0.6 \%$ vs $0.2 \%$; category $2,2.4 \%$ vs $0.8 \%$; category $3,3.1 \%$ vs $2.1 \%$; category 4 , $5.8 \%$ vs $5.6 \%$; and category $5,16.7 \%$ vs $16.5 \%$ ).

Conclusions: This study demonstrates differences in the reported number of patients and reported mortality in each STAT category among children undergoing various heart reoperations during the same hospitalization by classifying patients based on index operation compared with the operation of highest complexity. ( $\mathrm{J}$ Thorac Cardiovasc Surg 2018;156:1961-7)

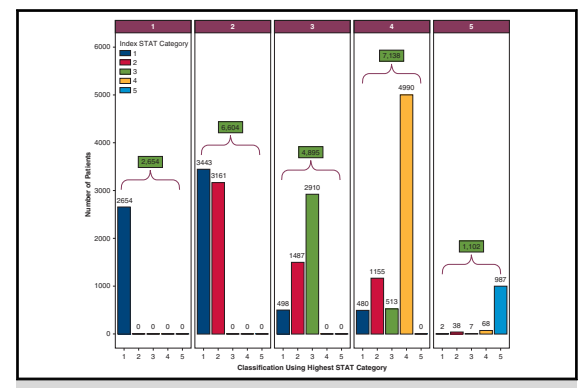

Contribution of patients in highest complexity STAT category by varied index categories.

\section{Central Message}

We demonstrate that reclassifying patients by operation of highest complexity (instead of by first operation) could influence the number of patients and the mortality rate in each STAT category.

\section{Perspective}

Because public reporting has become increasingly common in pediatric cardiac surgery, it is imperative to report accurate outcomes for individual hospitals. Using the first operation as the classifying operation (instead of highest complexity operation), it is possible to assign higher mortality to patients in lower STAT categories.

See Editorial Commentary page 1968

See Editorial page 1959.
With the advent of managed health care, increased emphasis is being placed on hospital outcomes. In pediatric heart surgery, risk-adjusted hospital outcomes have been

\footnotetext{
From the asection of Cardiac Critical Care, Methodist Children's Hospital, San Antonio, Tex; 'bepartment of Pediatrics, University of Arkansas for Medical Sciences, Little Rock, Ark; ' ${ }^{\mathrm{c}}$ Department of Cardiovascular Surgery, Tokyo Women's Medical University, Tokyo, Japan; ${ }^{\mathrm{d}}$ Department of Biostatistics, St.

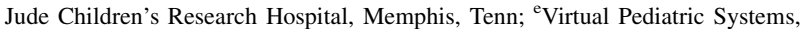
LLC, Los Angeles, Calif; f Department of Pediatrics, Seattle Children's Hospital, University of Washington School of Medicine, Seattle, Wash; and ${ }^{\mathrm{g}}$ Division of Pediatric Critical Care, Department of Pediatrics, Medical College of Wisconsin, Milwaukee, Wis.
}

made available to the public on a national level. ${ }^{1}$ Public reporting of risk-adjusted hospital outcomes allows families to make well-informed decisions when choosing the right

\footnotetext{
VPS data were provided by VPS, LLC. No endorsement or editorial restriction of the interpretation of these data or opinions of the authors has been implied or stated. Received for publication July 5, 2017; revisions received May 20, 2018; accepted for publication June 10, 2018; available ahead of print Aug 17, 2018.

Address for reprints: Punkaj Gupta, MBBS, Section of Cardiac Critical Care Methodist Children's Hospital, 7700 Floyd Curl Drive, San Antonio, TX 78229 (E-mail: punkaj_gupta@hotmail.com).

$0022-5223 / \$ 36.00$

Copyright (C) 2018 by The American Association for Thoracic Surgery

https://doi.org/10.1016/j.jtcvs.2018.06.035
} 


\section{Abbreviations and Acronyms}

$\mathrm{CPB}=$ cardiopulmonary bypass

$\mathrm{ECMO}=$ extracorporeal membrane oxygenation

ICU = intensive care unit

STAT $=$ Society of Thoracic Surgeons-European Association for Cardio-Thoracic Surgery

STS = Society of Thoracic Surgeons

VPS = Virtual Pediatric Systems LLC

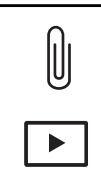

Scanning this QR code will

take you to a supplemental tables and video for the article.

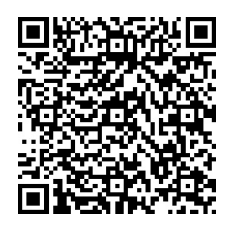

institution for a heart operation for their child. Currently, risk-adjusted outcomes in pediatric heart surgery are calculated on the basis of the first cardiovascular operation (with or without cardiopulmonary bypass) of each hospital admission (the index operation). ${ }^{2}$

For patients undergoing reoperations during the same hospital admission, it is not known whether reclassifying the hospital admission by the highest-complexity operation, instead of the index operation, would change the landscape of risk-adjusted outcomes. The issue of reclassifying the heart operations based on complexity is highlighted in the following example. An infant with congenital heart block and cardiomyopathy underwent placement of a permanent pacemaker (Society of Thoracic Surgeons-European Association for Cardio-Thoracic Surgery [STAT] mortality category 2) as the first cardiovascular operation before receiving heart transplant (STAT category 4) during the same hospital admission. Per the current practices, the mortality would be assigned to STAT mortality category 2 (instead of STAT mortality category 4 ).

To address these knowledge gaps, we evaluated the effect of reclassifying heart operations by the surgery of highest complexity (instead of index operation) on reported mortality at hospital discharge. We used data from the Virtual Pediatric Systems LLC (VPS) Database, a large, multiinstitutional, pediatric critical-care network with data from a diverse set of hospitals caring for critically ill children.

\section{MATERIALS AND METHODS \\ Data Source}

The VPS Database is an online pediatric critical-care network formed by the National Association of Children's Hospitals and Related Institutions, now part of the Children's Hospital Association, and Children's Hospital Los Angeles to develop a Web-based database for prospective data collection using standardized clinical data definitions, data quality control, and data analysis. ${ }^{5}$ The VPS Database is a prospective, observational cohort of consecutive pediatric intensive care unit (ICU) admissions from a diverse set of hospitals caring for children in the United States. Data are collected and entered by trained individuals, and VPS performs initial and quarterly interrater reliability (IRR) testing. The IRR concordance in the VPS Database is consistently above $95 \%$. There is extensive quality validation performed by VPS staff before the data are released for analysis, giving the data better reliability. The University of Arkansas for Medical Sciences Institutional Review Board for the Protection Of Human Subjects reviewed the study protocol and determined that querying de-identified patient data does not fall under the jurisdiction of the institutional review board review process.

\section{Patient Population}

This analysis focused on 6 years (2009-2015) of de-identified data available in the VPS Database. Patients aged $<18$ years who underwent operations (with or without cardiopulmonary bypass) for congenital heart disease at a participating ICU in the VPS Database were included. The initial study population included 51,047 ICU patients from 73 hospitals. For study purposes, only patients who underwent reoperations (ie, $\geq 2$ heart operations) during the same hospital admission were included. Therefore, we excluded patients who underwent only 1 heart operation during the hospital stay $(\mathrm{n}=28,005)$. We also excluded patients who lacked a STAT category for the index operation $(n=649)$. The final study population included 22,393 patients who were classified based on the index operation and on the complexity of the operation (the operation with the highest STAT mortality category of each hospital admission) (Table 1). The index operation of a hospitalization was defined as the first cardiac operation of that admission (ie, the first operation of an admission with operation type coronary artery bypass (CPB) or no CPB..$^{2-4}$

\section{Data Collection}

Data on demographic characteristics, heart operation, patient diagnosis, severity of illness score, and outcomes were collected. Specific demographic and severity of illness data included age, gender, failure to thrive, genetic disorder, low birth weight, and pediatric index of mortality 2 score. The data collected related to heart operation included complexity of heart operation, number of heart operations, and use of CPB pump during the cardiac surgery. We also collected data related to diagnosis and complications, such as use of extracorporeal membrane oxygenation (ECMO), use of a ventricular assist device, use of mechanical ventilation, pulmonary hypertension, renal failure, cardiac arrest, use of nitric oxide, brain hemorrhage, chylothorax, vocal cord paralysis, and the presence of hemothorax or pneumothorax after heart operation. Medical center characteristics were also collected, including the average annual number of cardiac surgery cases per center, presence of dedicated cardiac ICU, presence of residency and/or fellowship training programs, and presence of 24/7 in-house ICU attending physician coverage.

\section{Statistical Analysis}

We summarized demographic characteristics, severity of illness scores, comorbidities, procedures, and center-level variables with appropriate summary statistics, such as median and quartiles for quantitative variables and number and percent for categorical variables. Continuous variables were compared between 2 groups with a Mann-Whitney $U$ test, whereas categorical variables were compared with $\mathrm{a} \chi^{2}$ test of association. Observed rates of mortality and corresponding $95 \%$ confidence intervals were computed for each STAT category under each of the 2 classification systems. For each STAT category under the 2 classifications, we also used a logistic regression model to predict mortality rates using the following patient- and center-level variables: age (months), gender, genetic disorder (yes/no), failure to thrive (yes/no), CPB (yes/no), use of ECMO (yes/no), use of ventricular assist device (yes/no), use of mechanical ventilation (yes/no), pediatric index of mortality 2 score, pulmonary hypertension 
TABLE 1. Cross tabulation by Society of Thoracic Surgeons-European Association for Cardio-Thoracic Surgery (STAT) category for index operation and STAT category for highest complexity operation

\begin{tabular}{|c|c|c|c|c|c|c|}
\hline \multirow[b]{2}{*}{ STAT index operation } & \multicolumn{5}{|c|}{ STAT highest complexity operation } & \multirow[b]{2}{*}{ Total } \\
\hline & 1 & 2 & 3 & 4 & 5 & \\
\hline 1 & 2654 & 3443 & 498 & 480 & 2 & 7077 \\
\hline 2 & 0 & 3161 & 1487 & 1155 & 38 & 5841 \\
\hline 3 & 0 & 0 & 2910 & 513 & 7 & 3430 \\
\hline 4 & 0 & 0 & 0 & 4990 & 68 & 5058 \\
\hline 5 & 0 & 0 & 0 & 0 & 987 & 987 \\
\hline Total & 2654 & 6604 & 4895 & 7138 & 1102 & 22,393 \\
\hline
\end{tabular}

Bold represent common cases in both classification systems; that is, classification by index operation and classification by highest complexity operation. STAT, Society of Thoracic Surgeons-European Association for Cardio-Thoracic Surgery.

(yes/no), renal failure (yes/no), brain hemorrhage (yes/no), cardiac arrest (yes/no), use of nitric oxide (yes/no), dedicated cardiac ICU (yes/no), residency/fellowship training (yes/no), 24/7 physician coverage (yes/no), and average surgical cases per year.

We used hierarchical models using random intercepts at the hospital level to account for the clustering of patients within hospitals. Predicted probabilities and $95 \%$ confidence intervals were computed for each STAT category using the logistic regression model. Observed mortality rates were also computed by stratifying patients based on use of ECMO, cardiac arrest, and presence of at least 1 of the following postoperative complications: brain hemorrhage, chylothorax, vocal cord paralysis, hemothorax and/or pneumothorax, and renal failure. All statistical tests conducted were 2-sided using a significance level of 5\%. Data analyses were done with SAS/STAT software (version 9.4 for Windows, SAS Institute Inc, Cary, NC). Plots were generated with the ggplot2 package using the software R (R Foundation for Statistical Computing, Vienna, Austria).

\section{RESULTS}

A total of 22,393 patients were included in this study. Of these, 749 patients $(3.3 \%)$ experienced in-hospital mortality, and 21,664 patients $(96.7 \%)$ survived to hospital discharge. Cardiac arrest occurred in 820 patients $(3.7 \%)$, nitric oxide was utilized in 2,732 patients $(12.2 \%)$, and ECMO was deployed in 990 patients $(4.4 \%)$. The median annual center volume was 217 (interquartile range, 128373 ) cardiac surgery cases. Table 2 depicts the univariate comparisons for the study population between the survived and deceased patients.

We noted differences in the reported number of patients undergoing heart reoperations in varied STAT categories using the 2 classification systems. By classifying reoperations based on the highest-complexity operation, we observed a decrease in the number of patients in the STAT 1 category compared with classification by the index operation (index, $\mathrm{n}=7077$; highest complexity, $\mathrm{n}=2654$ ) (Table 1). Of 4423 patients currently classified as STAT 1 category by the index operation classification, 3443 patients were classified as STAT 2 by the highest-complexity operation classification, 498 patients as STAT 3, 480 patients as STAT 4, and 2 patients as STAT 5 (Figure 1). In contrast, for other STAT categories, we noted an increase in the number of patients in the highest-complexity operation classification, compared with index operation classification, as the patients moved from lower STAT categories to higher STAT categories. For example, under the highest-complexity operation classification, there were 6604 patients in the STAT 2 category. However, the index operation classification placed 5841 patients in the STAT 2 category. Similar trends were noted for STAT categories 3, 4, and 5 (Table 1). The details of heart operations (with their STAT categories) in 2 classification systems are provided in Table E1.

We noted higher observed mortality in all STAT categories when patients were classified by index operation compared with classification by the highest complexity operation (index operation vs highest complexity operation: STAT category $1,0.6 \%$ vs $0.2 \%$; STAT category $2,2.4 \%$ vs $0.8 \%$; STAT category $3,3.1 \%$ vs $2.1 \%$; STAT category 4 , $5.8 \%$ vs $5.6 \%$; and STAT category $5,16.7 \%$ vs $16.5 \%$ ) (Table 3). In models adjusted for patient and center characteristics, we noted similar trends of higher predicted mortality among patients classified by index operation, compared with classification using the highest complexity operation (Table 3). The c-statistic (95\% confidence interval) using the index-operation classification to predict mortality was 0.77 (95\% confidence interval, $0.75-0.78)$ and using the highest complexity operation classification was 0.89 (95\% confidence interval, 0.86-0.91). We also calculated observed and expected mortality using 2 classification systems at a participating center in the database. We noted lower mortality and lower observed-to-expected mortality ratios using the highest complexity classification compared with the index operation classification (Table E2).

We then evaluated the use of ECMO, incidence of postoperative cardiac arrest, and incidence of postoperative complications using the 2 classification systems (Table 4). We noted a higher incidence of postoperative ECMO, cardiac arrest (and associated mortality), and postoperative complications in the majority of STAT categories using the index operation classification system compared with the highest complexity operation 
TABLE 2. Patient and center characteristics

\begin{tabular}{|c|c|c|c|c|c|}
\hline Characteristic & $\mathbf{n}$ & $\begin{array}{l}\text { All patients } \\
(\mathrm{N}=\mathbf{2 2 , 3 9 3})\end{array}$ & $\begin{array}{c}\text { Survived } \\
(\mathrm{n}=\mathbf{2 1 , 6 4 4 )}\end{array}$ & $\begin{array}{l}\text { Deceased } \\
(\mathrm{n}=749)\end{array}$ & $P$ value \\
\hline Age, mo & 22,393 & $5.2(0.8$ to 20$)$ & $5.3(1$ to 21.5$)$ & $0.3(0$ to 4.6$)$ & $<.0001$ \\
\hline Weight-for-age $z$ score & 22,257 & $-1.06(-2.13$ to -0.12$)$ & $-1.06(-2.11$ to -0.09$)$ & $-1.08(-2.33$ to -0.8$)$ & $<.0001$ \\
\hline Male gender & 22,390 & $12,336(55.1)$ & $11,929(55.1)$ & $407(54.3)$ & .672 \\
\hline Genetic disorder & 22,393 & $1007(4.5)$ & $952(4.4)$ & $55(7.3)$ & .0001 \\
\hline Failure to thrive & 22,393 & $2220(9.9)$ & $2134(9.9)$ & $86(11.5)$ & .144 \\
\hline $\mathrm{CPB}$ use & 22,393 & $16,273(72.7)$ & $15,918(73.5)$ & 355 (47.4) & $<.0001$ \\
\hline Use of ECMO & 22,393 & $990(4.4)$ & $523(2.4)$ & $467(62.3)$ & $<.0001$ \\
\hline Use of VAD & 22,393 & $28(0.1)$ & $21(0.1)$ & $7(0.9)$ & $<.0001$ \\
\hline $\begin{array}{l}\text { Total number of surgeries } \\
2 \\
3 \\
\geq 4\end{array}$ & 22,393 & $\begin{array}{r}12,971(57.9) \\
6555(29.3) \\
2867(12.8)\end{array}$ & $\begin{array}{r}12,666(58.5) \\
6336(29.3) \\
2642(12.2)\end{array}$ & $\begin{array}{l}305(40.7) \\
219(29.2) \\
225(30.0)\end{array}$ & $<.0001$ \\
\hline $\begin{array}{l}\text { STAT index operation } \\
\qquad \begin{array}{l}1 \\
2 \\
3 \\
4 \\
5\end{array}\end{array}$ & 22,393 & $\begin{array}{c}7077(31.6) \\
5841(26.1) \\
3430(15.3) \\
5058(22.6) \\
987(4.4)\end{array}$ & $\begin{array}{c}7035(32.5) \\
5699(26.3) \\
3323(15.4) \\
4765(22.0) \\
822(3.8)\end{array}$ & $\begin{array}{c}42(5.6) \\
142(19.0) \\
107(14.3) \\
293(39.1) \\
165(22.0)\end{array}$ & $<.0001$ \\
\hline $\begin{array}{l}\text { STAT highest complexity } \\
1 \\
2 \\
3 \\
4 \\
5\end{array}$ & 22,393 & $\begin{array}{l}2654(11.9) \\
6604(29.5) \\
4895(21.9) \\
7138(31.9) \\
1102(4.9)\end{array}$ & $\begin{array}{c}2650(12.2) \\
6550(30.3) \\
4790(22.1) \\
6734(31.1) \\
920(4.3)\end{array}$ & $\begin{array}{c}4(0.5) \\
54(7.2) \\
105(14.0) \\
404(53.9) \\
182(24.3)\end{array}$ & $<.0001$ \\
\hline PIM-2 score & 22,393 & $-3.91(-4.42$ to -3.17$)$ & $-3.93(-4.43$ to -3.22$)$ & $-2.83(-3.75$ to -1.86$)$ & $<.0001$ \\
\hline Use of mechanical ventilation & 22,393 & $18,579(83.0)$ & $17,841(82.4)$ & $738(98.5)$ & $<.0001$ \\
\hline Pulmonary hypertension & 22,393 & $1511(6.7)$ & $1382(6.4)$ & $129(17.2)$ & $<.0001$ \\
\hline Renal failure & 22,393 & $1189(5.3)$ & $902(4.2)$ & $287(38.3)$ & $<.0001$ \\
\hline Cardiac arrest & 22,393 & $820(3.7)$ & $530(2.4)$ & $290(38.7)$ & $<.0001$ \\
\hline Use of nitric oxide & 22,393 & $2732(12.2)$ & $2370(10.9)$ & $362(48.3)$ & $<.0001$ \\
\hline Brain hemorrhage & 22,393 & $527(2.4)$ & $421(1.9)$ & $106(14.2)$ & $<.0001$ \\
\hline Chylothorax & 22,393 & $405(1.8)$ & $360(1.7)$ & $45(6.0)$ & $<.0001$ \\
\hline Vocal cord paralysis & 22,393 & $606(2.7)$ & $583(2.7)$ & $23(3.1)$ & .532 \\
\hline Hemothorax/pneumothorax & 22,393 & $563(2.5)$ & $501(2.3)$ & $62(8.3)$ & $<.0001$ \\
\hline Residency/fellowship training & 22,393 & $20,009(89.4)$ & $19,337(89.3)$ & $672(89.7)$ & .741 \\
\hline Dedicated cardiac ICU & 22,393 & $11,633(51.9)$ & $11,286(52.1)$ & $347(46.3)$ & .0017 \\
\hline $24 / 7$ physician coverage & 22,393 & $12,091(54.0)$ & $11,666(53.9)$ & $425(56.7)$ & .125 \\
\hline Average surgical cases per year & 22,393 & 217 (128 to 373$)$ & 217 (128 to 373$)$ & $186(127$ to 292$)$ & $<.0001$ \\
\hline
\end{tabular}

Categorical variables are presented as $\mathrm{n}(\%)$. Continuous variables are presented as interquartile range, IQR as median (25th percentile, 75 th percentile). $C P B$, Cardiopulmonary bypass; $E C M O$, extracorporeal membrane oxygenation; VAD, ventricular assist device; STAT, Society of Thoracic Surgeons-European Association for Cardio-Thoracic Surgery; $P I M-2$, pediatric index of mortality $2 ; I C U$, intensive care unit.

classification system. We also noted similar trends of higher mortality in the majority of STAT categories in all of these subgroups when the index operation classification system was used.

\section{DISCUSSION}

This large, multi-institutional, observational study demonstrates differences in the reported number of patients undergoing heart reoperations in varied STAT categories by 

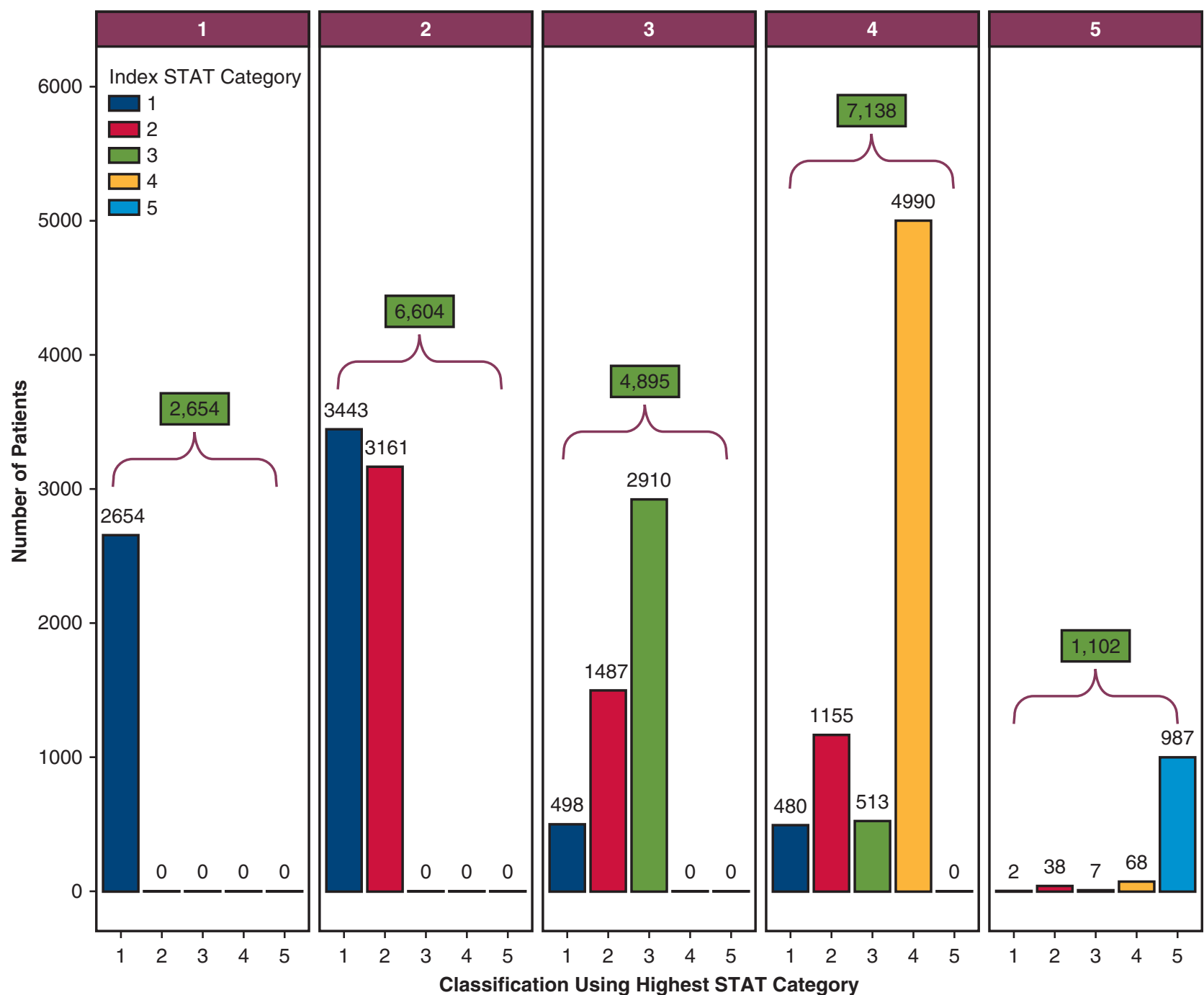

FIGURE 1. Contribution of patients in individual highest complexity Society of Thoracic Surgeons-European Association for Cardio-Thoracic Surgery (STAT) category (each panel on $x$-axis) by varied index STAT categories (each bar within each panel). For example, using highest complexity operations as the classification system, the patients in STAT category 3 received 498 patients from index STAT category 1, 1487 patients from index STAT category 2 , and 2910 patients index STAT category 3.

using 2 classification systems, namely index operation or highest complexity operation as the classifying operation for the hospital admission. Our study demonstrates that the number of patients placed in the STAT 1 category increases by approximately 2.5 times if the index operation is used as the classifying operation instead of the highest

TABLE 3. Observed and predicted mortality among the study patients by classifying the patients using index operations and highest complexity operations

\begin{tabular}{|c|c|c|c|c|}
\hline \multirow[b]{3}{*}{ All patients } & \multicolumn{2}{|c|}{ Index operation } & \multicolumn{2}{|c|}{ Highest complexity operation } \\
\hline & & Predicted $(95 \%$ confidence & & Predicted $(95 \%$ confidence \\
\hline & Observed & interval) & Observed & interval) \\
\hline STAT category 1 & $42 / 7077(0.6 \%)$ & $0.7 \%(0.6 \%-0.9 \%)$ & $4 / 2654(0.2 \%)$ & $0.2 \%(0.0 \%-0.3 \%)$ \\
\hline STAT category 2 & $142 / 5841(2.4 \%)$ & $2.1 \%(1.9 \%-2.3 \%)$ & $54 / 6604(0.8 \%)$ & $0.8 \%(0.7 \%-0.9 \%)$ \\
\hline STAT category 3 & $107 / 3430(3.1 \%)$ & $3.0 \%(2.7 \%-3.3 \%)$ & $105 / 4895(2.1 \%)$ & $2.1 \%(1.9 \%-2.3 \%)$ \\
\hline STAT category 4 & $293 / 5058(5.8 \%)$ & $5.9 \%(5.5 \%-6.3 \%)$ & $404 / 7138(5.6 \%)$ & $5.6 \%(5.2 \%-5.9 \%)$ \\
\hline STAT Category 5 & $165 / 987(16.7 \%)$ & $16.2 \%(14.7 \%-17.8 \%)$ & $182 / 1102(16.5 \%)$ & $16.3 \%(14.8 \%-17.7 \%)$ \\
\hline
\end{tabular}

STAT, Society of Thoracic Surgeons-European Association for Cardio-Thoracic Surgery. 
TABLE 4. Incidence (and associated mortality) of extracorporeal membrane oxygenation (ECMO), cardiac arrest, and postoperative complications among the study patients by classifying the patients using index operations and highest complexity operations

\begin{tabular}{|c|c|c|c|c|}
\hline \multirow[b]{2}{*}{ Variable } & \multicolumn{2}{|c|}{ Index operation } & \multicolumn{2}{|c|}{ Highest complexity operation } \\
\hline & Incidence & Mortality & Incidence & Mortality \\
\hline \multicolumn{5}{|l|}{ STAT category 1} \\
\hline Use of ECMO & $63 / 7077(0.9 \%)$ & $21 / 63(33.3 \%)$ & $10 / 2654(0.4 \%)$ & $1 / 10(10.0 \%)$ \\
\hline Cardiac arrest & $72 / 7077(1.0 \%)$ & $12 / 72(16.6 \%)$ & $21 / 2654(0.8 \%)$ & $3 / 21(14.3 \%)$ \\
\hline Complications & $363 / 7077(5.1 \%)$ & $18 / 363(4.9 \%)$ & $101 / 2654(3.8 \%)$ & $2 / 101(2.0 \%)$ \\
\hline \multicolumn{5}{|l|}{ STAT category 2} \\
\hline Use of ECMO & $163 / 5841(2.8 \%)$ & $73 / 163(44.8 \%)$ & $68 / 6604(1.0 \%)$ & $20 / 68(29.4 \%)$ \\
\hline Cardiac arrest & $149 / 5841(2.6 \%)$ & $47 / 149(31.5 \%)$ & $95 / 6604(1.4 \%)$ & $20 / 95(21.0 \%)$ \\
\hline Complications & $683 / 5841(11.7 \%)$ & $71 / 683(10.4 \%)$ & $421 / 6604(6.4 \%)$ & $24 / 421(5.7 \%)$ \\
\hline \multicolumn{5}{|l|}{ STAT category 3} \\
\hline Use of ECMO & $145 / 3430(4.2 \%)$ & $59 / 145(40.7 \%)$ & $130 / 4895(2.7 \%)$ & $54 / 130(41.5 \%)$ \\
\hline Cardiac arrest & $124 / 3430(3.6 \%)$ & $38 / 124(30.6 \%)$ & $119 / 4895(2.4 \%)$ & $33 / 119(27.7 \%)$ \\
\hline Complications & $480 / 3430(14.0 \%)$ & $50 / 480(10.4 \%)$ & $676 / 4895(13.8 \%)$ & $51 / 676(7.5 \%)$ \\
\hline \multicolumn{5}{|l|}{ STAT category 4} \\
\hline Use of ECMO & $395 / 5058(7.8 \%)$ & $190 / 395(48.1 \%)$ & $530 / 7138(7.4 \%)$ & $255 / 530(48.1 \%)$ \\
\hline Cardiac arrest & $325 / 5058(6.4 \%)$ & $115 / 325(35.3 \%)$ & $422 / 7138(5.9 \%)$ & $151 / 422(35.7 \%)$ \\
\hline Complications & $858 / 5058(17.0 \%)$ & $138 / 858(16.0 \%)$ & $1151 / 7138(16.1 \%)$ & $193 / 1151(16.7 \%)$ \\
\hline \multicolumn{5}{|l|}{ STAT category 5} \\
\hline Use of ECMO & $224 / 987(22.7 \%)$ & $124 / 224(55.3 \%)$ & $252 / 1102(22.9 \%)$ & $137 / 252(54.4 \%)$ \\
\hline Cardiac arrest & $150 / 987(15.2 \%)$ & $78 / 150(52.0 \%)$ & $163 / 1102(14.8 \%)$ & $83 / 163(50.9 \%)$ \\
\hline Complications & $358 / 987(36.3 \%)$ & $103 / 358(28.7 \%)$ & $393 / 1102(35.7 \%)$ & $110 / 393(27.9 \%)$ \\
\hline
\end{tabular}

Postoperative complications included brain hemorrhage, chylothorax, vocal cord paralysis, hemothorax/pneumothorax, and renal failure. STAT, Society of Thoracic SurgeonsEuropean Association for Cardio-Thoracic Surgery; ECMO, extracorporeal membrane oxygenation.

complexity operation. We also found that the in-hospital mortality for each STAT category varies with the 2 classification systems, with higher mortality noted in STAT categories 1,2, and 3 with index operation as the classifying operation. Postoperative complications also varied in each STAT category in the 2 classifications systems (Video 1 ).

In recent years, hospital performance has been publicly reported by various organizations, including the Society of Thoracic Surgeons (STS) and U.S. News and World Report. ${ }^{1,6,7}$ Recently, the STS developed a mortality risk model from STS Congenital Heart Surgery Database using index operation as the classifying operation., ${ }^{2,3}$ Using these risk models, the STS Database reports the mortality data for individual hospitals for each STAT category. Our study demonstrates that the mortality data will differ if the highest complexity operation is used as the classifying operation, instead of the index operation, especially for the lower STAT categories among children undergoing heart reoperations during the same hospitalization.

We also reported that the incidence of cardiac arrest, postoperative complications, and use of ECMO was higher in the majority of STAT categories when using the index operation as the classifying operation. In the existing literature, data on cardiac arrest, postoperative complications, and ECMO use are reported using the index operation as the classifying operation. ${ }^{8-11}$ With this method, it is possible that some of these complications may have been misclassified to a lower STAT category.

We demonstrate that the landscape of heart operations and associated outcomes change by classifying the operations using highest complexity operation, instead of index operation as the classifying operation for the hospital admission. By classifying reoperations based on the highest complexity operation, we observed a decrease in the number of patients (and associated mortality) in the STAT 1 category, compared with classification by the index operation. We noted lower mortality for other STAT categories (particularly STAT categories 1, 2, and 3) using highest complexity operation, instead of classification by the index operation. We also noted that the landscape of complications associated with heart operations also change by classifying the operations using the highest complexity operation, instead of the index operation as the classifying operation for the hospital admission. We noted lower complication rate by classifying operation using highest complexity operation, instead of classification by the index operation in all STAT categories (particularly STAT categories 1,2, and 3).

Our study has several potential limitations. Not all US pediatric hospitals participate in the VPS Database. Nonetheless, the present report represents the most inclusive evaluation to date, with data from $>70$ hospitals. As with all multicenter registries, data analysis may be limited by 


\section{Reclassifying by Highest Complexity Operation Rather than First Operation Impacts Mortality after Pediatric Heart Surgery}

Punkaj Gupta, MBBS; Mallikarjuna Rettiganti, PhD; Takeshi Shinkawa, MD; Jeffrey M. Gossett, MS; Nancy Brundage, RN, BSN; Howard E. Jeffries, MD, MBA; Rebecca A. Russell, MD

VIDEO 1. Introduction to the study. Video available at: https://www.jtcvs. org/article/S0022-5223(18)31780-X/fulltext.

data integrity, compliance, and validation across multiple sites. However, the rigorous centralized abstractor certification process, uniform data collection tools and training, consistent definitions, electronic automated data feedback, and large sample size minimize these sources of bias. Because our data came from a clinical data set collected prospectively, rather than an administrative dataset, we expect that the diagnoses and procedure codes are more accurate. VPS data are collected and entered by trained individuals. Moreover, extensive quality validation is performed by VPS staff before the data are released. The IRR concordance in the VPS Database is consistently above $95 \%$. Therefore, we expect that the results of our study are within reasonable accuracy. We were also limited by consideration of variables collected in the VPS Database.

Due to the retrospective nature of this study, we could not account for the clinical reasons (such as expected strategy for a certain heart defect or wrong clinical judgment or technical imperfections) that led to the reoperation with a higher complexity operation during the same hospital stay. In some cases, reoperation performed may be a marker of quality, and may not necessarily be reflective of the innate baseline complexity or severity of illness of the patient. Therefore, using either first (or index) operation or operation with the highest complexity operation may be an inaccurate method to define the case mix of the patients. An alternative strategy could be to account for the case mix using baseline cardiac diagnosis; however, it requires rigorous modeling and validation using the STS Database.

\section{CONCLUSIONS}

This multicenter study demonstrates differences in the reported number of patients and the reported mortality in each
STAT category among children undergoing heart reoperations of varying complexity during the same hospitalization when classifying patients by index operation versus by the operation of highest complexity. This variation in classification could influence the public reporting of outcomes. Therefore, we recommend replicating this study with another national database, such as the STS Database.

\section{Conflict of Interest Statement}

Authors have nothing to disclose with regard to commercial support.

\section{References}

1. Society of Thoracic Surgeons. Congenital heart surgery public reporting Available at: https://www.sts.org/congenital-public-reporting-module-search. Accessed June 23, 2017.

2. O’Brien SM, Jacobs JP, Pasquali SK, Gaynor JW, Karamlou T, Welke KF, et al The Society of Thoracic Surgeons congenital heart surgery database mortality risk model: part 1-statistical methodology. Ann Thorac Surg. 2015;100:1054-62.

3. Jacobs JP, O'Brien SM, Pasquali SK, Gaynor JW, Mayer JE Jr, Karamlou T, et al. The Society of Thoracic Surgeons congenital heart surgery database mortality risk model: part 2-clinical application. Ann Thorac Surg. 2015;100:1063-8.

4. Jacobs JP, Mavroudis C, Quintessenza JA, Chai PJ, Pasquali SK, Hill KD, et al. Reoperations for pediatric and congenital heart disease: an analysis of the Society of Thoracic Surgeons (STS) congenital heart surgery database. Semin Thorac Cardiovasc Surg Pediatr Card Surg Annu. 2014;17:2-8.

5. VPS LLC. Database. Available at: http://www.myvps.org. Accessed June 23 , 2017.

6. OptumHealth. Congenital heart disease resource services. Available at: https:// www.myoptumhealthcomplexmedical.com/gateway/public/chd/chd.jsp. Accessed June 23, 2017

7. U.S. News \& World Report's annual ranking of best children's hospitals. Available at: http://health.usnews.com/best-hospitals/pediatric-rankings. Accessed June 23,2017

8. Gupta P, Jacobs JP, Pasquali SK, Hill KD, Gaynor JW, O'Brien SM, et al. Epidemiology and outcomes following in-hospital cardiac arrest after pediatric cardiac surgery. Ann Thorac Surg. 2014;98:2138-44.

9. Mascio CE, Austin EH III, Jacobs JP, Jacobs ML, Wallace AS, He X, et al. Perioperative mechanical circulatory support in children: an analysis of the Society of Thoracic Surgeons congenital heart surgery database. J Thorac Cardiovasc Surg. 2014;147:658-64.

10. Jacobs ML, O'Brien SM, Jacobs JP, Mavroudis C, Lacour-Gayet F, Pasquali SK, et al. An empirically based tool for analyzing morbidity associated with operations for congenital heart disease. J Thorac Cardiovasc Surg. 2013;145:1046-57.

11. Pasquali SK, He X, Jacobs ML, Shah SS, Peterson ED, Gaies MG, et al. Excess costs associated with complications and prolonged length of stay after congenital heart surgery. Ann Thorac Surg. 2014;98:1660-6.

Key Words: pediatric heart surgery, reclassification, index operation, highest complexity operation 
TABLE E1. Details of cardiac procedures in the 2 classification systems used in our study population

\begin{tabular}{|c|c|c|c|}
\hline $\begin{array}{l}\text { Highest } \\
\text { STAT category }\end{array}$ & Highest STAT procedure & $\begin{array}{l}\text { Index STAT } \\
\text { category }\end{array}$ & Index STAT procedure \\
\hline 5 & Norwood/stage 1 palliation & 4 & Pulmonary artery banding \\
\hline 5 & Norwood/stage 1 palliation & 4 & $\begin{array}{l}\text { Hybrid approach "Stage 1," Application of RPA and } \\
\text { LPA bands }\end{array}$ \\
\hline 5 & Norwood/stage 1 palliation & 4 & Atrial septal defect creation (surgical) \\
\hline 5 & $\begin{array}{l}\text { Damus-Kaye-Stansel procedure } \\
\text { (without arch reconstruction) }\end{array}$ & 4 & Aortic arch repair \\
\hline 5 & Norwood/stage 1 palliation & 4 & $\begin{array}{l}\text { Total anomalous pulmonary venous connection } \\
\text { repair }\end{array}$ \\
\hline 5 & $\begin{array}{l}\text { Damus-Kaye-Stansel procedure } \\
\text { (without arch reconstruction) }\end{array}$ & 4 & $\begin{array}{l}\text { Hybrid approach "Stage 1," Application of RPA and } \\
\text { LPA bands }\end{array}$ \\
\hline 5 & $\begin{array}{l}\text { Damus-Kaye-Stansel procedure } \\
\text { (without arch reconstruction) }\end{array}$ & 4 & Pulmonary artery banding \\
\hline 5 & $\begin{array}{l}\text { Damus-Kaye-Stansel procedure } \\
\text { (without arch reconstruction) }\end{array}$ & 4 & Shunt, systemic to pulmonary \\
\hline 5 & Norwood/stage 1 palliation & 4 & $\begin{array}{l}\text { Hybrid approach "Stage 1," Stent placement in } \\
\text { arterial duct }\end{array}$ \\
\hline 5 & $\begin{array}{l}\text { Damus-Kaye-Stansel procedure } \\
\text { (without arch reconstruction) }\end{array}$ & 3 & Coarctation repair, patch aortoplasty \\
\hline 5 & $\begin{array}{l}\text { Damus-Kaye-Stansel procedure } \\
\text { (without arch reconstruction) }\end{array}$ & 3 & Rastelli \\
\hline 5 & $\begin{array}{l}\text { Damus-Kaye-Stansel procedure } \\
\text { (without arch reconstruction) }\end{array}$ & 2 & $\begin{array}{l}\text { Superior vena cava-pulmonary artery shunt (Glenn)/ } \\
\text { hemi-Fontan }\end{array}$ \\
\hline 5 & $\begin{array}{l}\text { Damus-Kaye-Stansel procedure } \\
\text { (without arch reconstruction) }\end{array}$ & 2 & Fontan operation \\
\hline 5 & $\begin{array}{l}\text { Damus-Kaye-Stansel procedure } \\
\text { (without arch reconstruction) }\end{array}$ & 2 & Ross procedure \\
\hline 5 & $\begin{array}{l}\text { Damus-Kaye-Stansel procedure } \\
\text { (without arch reconstruction) }\end{array}$ & 2 & Aortic stenosis repair \\
\hline 5 & $\begin{array}{l}\text { Damus-Kaye-Stansel procedure } \\
\text { (without arch reconstruction) }\end{array}$ & 2 & Tricuspid valvuloplasty, open \\
\hline 5 & $\begin{array}{l}\text { Damus-Kaye-Stansel procedure } \\
\text { (without arch reconstruction) }\end{array}$ & 1 & Superior vena cava-pulmonary artery shunt (Glenn) \\
\hline 4 & Pulmonary artery debanding & 3 & AV canal repair \\
\hline 4 & Aortic arch repair & 3 & Coarctation repair \\
\hline 4 & Atrial septal fenestration & 3 & Arterial switch operation for TGA \\
\hline 4 & Atrial septal defect creation (surgical) & 3 & AV canal repair \\
\hline 4 & Pulmonary artery banding & 3 & AV canal repair \\
\hline 4 & Pulmonary artery banding & 3 & Coarctation repair \\
\hline 4 & Pulmonary artery debanding & 3 & Arterial switch operation for TGA \\
\hline 4 & Mitral valve replacement & 3 & AV canal repair \\
\hline 4 & Shunt, systemic to pulmonary & 3 & Right ventricle-pulmonary artery conduit \\
\hline 4 & Aortic arch repair & 3 & AV canal repair \\
\hline 4 & Common atrioventricular valvuloplasty & 3 & AV canal repair \\
\hline 4 & Unifocalization MAPCA (s) & 3 & Right ventricle-pulmonary artery conduit \\
\hline 4 & Aortic root replacement & 3 & Aortic valve replacement \\
\hline 4 & Mitral valve replacement & 3 & Aortic valve replacement \\
\hline
\end{tabular}


TABLE E1. Continued

\begin{tabular}{|c|c|c|c|}
\hline $\begin{array}{c}\text { Highest } \\
\text { STAT category }\end{array}$ & Highest STAT procedure & $\begin{array}{c}\text { Index STAT } \\
\text { category }\end{array}$ & Index STAT procedure \\
\hline 4 & Mitral valve replacement & 3 & Konno procedure \\
\hline 4 & Aortic arch repair & 3 & Right ventricle-pulmonary artery conduit \\
\hline 4 & Unifocalization MAPCA (s) & 3 & Rastelli \\
\hline 4 & Aortic arch repair & 3 & Aortic valve replacement \\
\hline 4 & Aortic dissection repair & 3 & Right ventricle-pulmonary artery conduit \\
\hline 4 & Ebstein's repair & 3 & Right ventricle-pulmonary artery conduit \\
\hline 4 & Mitral valve replacement & 3 & Right ventricle-pulmonary artery conduit \\
\hline 4 & Shunt, systemic to pulmonary & 3 & Pulmonary atresia repair \\
\hline 4 & Shunt, systemic to pulmonary & 3 & $\begin{array}{l}\text { Pulmonary atresia - VSD (including tetralogy of } \\
\text { Fallot, pulmonary artery) repair }\end{array}$ \\
\hline 4 & $\begin{array}{l}\text { Total anomalous pulmonary venous connection } \\
\text { repair }\end{array}$ & 3 & AV canal repair \\
\hline 4 & Aortic arch repair & 3 & Hemi-Fontan \\
\hline 4 & Aortic arch repair & 3 & Pulmonary artery procedure \\
\hline 4 & Aortic arch repair & 3 & Ross procedure \\
\hline 4 & Aortic arch repair & 3 & Shunt, ligation, and takedown \\
\hline 4 & Aortic dissection repair & 3 & AV canal repair \\
\hline 4 & Aortic root replacement & 3 & AV canal repair \\
\hline 4 & Aortic root replacement & 3 & Konno procedure \\
\hline 4 & Aortic root replacement & 3 & Right ventricle-pulmonary artery conduit \\
\hline 4 & Common atrioventricular valvuloplasty & 3 & Shunt, ligation, and takedown \\
\hline 4 & Ebstein's repair & 3 & Aneurysm repair \\
\hline 4 & Heart transplant & 3 & AV canal repair \\
\hline 4 & Heart transplant & 3 & Konno procedure \\
\hline 4 & Unifocalization MAPCA (s) & 3 & Pulmonary artery procedure \\
\hline 4 & Unifocalization MAPCA (s) & 3 & Right ventricle-pulmonary artery conduit \\
\hline 4 & Atrial septal defect creation (surgical) & 2 & $\begin{array}{l}\text { Superior vena cava-pulmonary artery shunt (Glenn)/ } \\
\text { hemi-Fontan }\end{array}$ \\
\hline 4 & Atrial septal defect creation (surgical) & 2 & Superior vena cava-pulmonary artery shunt (Glenn) \\
\hline 4 & Pulmonary artery banding & 2 & $\begin{array}{l}\text { Superior vena cava-pulmonary artery shunt (Glenn)/ } \\
\text { hemi-Fontan }\end{array}$ \\
\hline 4 & Pulmonary artery banding & 2 & Coarctation repair \\
\hline 4 & Pulmonary artery banding & 2 & Superior vena cava-pulmonary artery shunt (Glenn) \\
\hline 4 & Atrial septal defect creation (surgical) & 2 & Fontan operation \\
\hline 4 & Pulmonary artery debanding & 2 & $\begin{array}{l}\text { Superior vena cava-pulmonary artery shunt (Glenn)/ } \\
\text { hemi-Fontan }\end{array}$ \\
\hline 4 & Atrial septal defect creation (surgical) & 2 & Tetralogy of Fallot repair \\
\hline 4 & Aortic arch repair & 2 & Coarctation repair \\
\hline 4 & Aortic arch repair & 2 & $\begin{array}{l}\text { Superior vena cava-pulmonary artery shunt (Glenn)/ } \\
\text { hemi-Fontan }\end{array}$ \\
\hline 4 & Shunt, systemic to pulmonary & 2 & Pulmonary artery procedure \\
\hline 4 & Pulmonary artery debanding & 2 & Superior vena cava-pulmonary artery shunt (Glenn) \\
\hline 4 & Pulmonary artery debanding & 2 & Ventricular septal defect repair \\
\hline 4 & Pulmonary artery debanding & 2 & Fontan operation \\
\hline 4 & Shunt, systemic to pulmonary & 2 & RVOT procedure \\
\hline
\end{tabular}


TABLE E1. Continued

\begin{tabular}{|c|c|c|c|}
\hline $\begin{array}{l}\text { Highest } \\
\text { STAT category }\end{array}$ & Highest STAT procedure & $\begin{array}{l}\text { Index STAT } \\
\text { category }\end{array}$ & Index STAT procedure \\
\hline 4 & Mitral valve replacement & 2 & Mitral valvuloplasty, open \\
\hline 4 & Shunt, systemic to pulmonary & 2 & $\begin{array}{l}\text { Superior vena cava-pulmonary artery shunt (Glenn)/ } \\
\text { hemi-Fontan }\end{array}$ \\
\hline 4 & Common atrioventricular valvuloplasty & 2 & Fontan operation \\
\hline 4 & Common atrioventricular valvuloplasty & 2 & $\begin{array}{l}\text { Superior vena cava-pulmonary artery shunt (Glenn)/ } \\
\text { hemi-Fontan }\end{array}$ \\
\hline 4 & Shunt, systemic to pulmonary & 2 & Tetralogy of Fallot repair \\
\hline 4 & Shunt, systemic to pulmonary & 2 & Tricuspid valvuloplasty, open \\
\hline 4 & Aortic arch repair & 2 & Superior vena cava-pulmonary artery shunt (Glenn) \\
\hline 4 & Pulmonary venous stenosis repair & 2 & $\begin{array}{l}\text { Superior vena cava-pulmonary artery shunt (Glenn)/ } \\
\text { hemi-Fontan }\end{array}$ \\
\hline 4 & Aortic arch repair & 2 & Aortic stenosis repair \\
\hline 4 & Aortic arch repair & 2 & Fontan operation \\
\hline 4 & Atrial septal defect creation (surgical) & 2 & Tricuspid valvuloplasty, open \\
\hline 4 & Aortic arch repair & 2 & AP window repair \\
\hline 4 & Atrial septal defect creation (surgical) & 2 & Mitral valvuloplasty, open \\
\hline 4 & Atrial septal defect creation (surgical) & 2 & RVOT procedure \\
\hline 4 & Aortic arch repair & 2 & Aortic Root Replacement \\
\hline 4 & Pulmonary venous stenosis repair & 2 & Superior vena cava-pulmonary artery shunt (Glenn) \\
\hline 4 & Unifocalization MAPCA (s) & 2 & Tetralogy of Fallot repair \\
\hline 4 & Aortic arch repair & 2 & Tetralogy of Fallot repair \\
\hline 4 & Pulmonary venous stenosis repair & 2 & Aortic stenosis repair \\
\hline 4 & Aortic arch repair & 2 & Mitral valvuloplasty, open \\
\hline 4 & Mitral valve replacement & 2 & Aortic root replacement \\
\hline 4 & Pulmonary venous stenosis repair & 2 & Pulmonary valvuloplasty, open \\
\hline 4 & Pulmonary venous stenosis repair & 2 & Tricuspid valvuloplasty, open \\
\hline 4 & Shunt, systemic to pulmonary & 2 & Pulmonary valvuloplasty, open \\
\hline 4 & Unifocalization MAPCA (s) & 2 & Tetralogy of Fallot repair \\
\hline 4 & Heart transplant & 2 & Pacemaker insertion/revision \\
\hline 4 & Mitral valve replacement & 2 & Tricuspid valvuloplasty, open \\
\hline 4 & Pulmonary venous stenosis repair & 2 & RVOT procedure \\
\hline 4 & Pulmonary venous stenosis repair & 2 & Tetralogy of Fallot repair \\
\hline 4 & $\begin{array}{l}\text { Total anomalous pulmonary venous connection } \\
\text { repair }\end{array}$ & 2 & Tetralogy of Fallot repair \\
\hline 4 & Aortic arch repair & 2 & Ross procedure \\
\hline 4 & Aortic arch repair & 2 & Ventricular septal defect repair \\
\hline 4 & Aortic dissection repair & 2 & Superior vena cava-pulmonary artery shunt (Glenn) \\
\hline 4 & Aortic root replacement & 2 & Mitral valvuloplasty, open \\
\hline 4 & Atrial septal defect creation (surgical) & 2 & Aortic stenosis repair \\
\hline 4 & Heart transplant & 2 & Mitral valvuloplasty, open \\
\hline 4 & Heart transplant & 2 & RVOT procedure \\
\hline 4 & Mitral valve replacement & 2 & Aortic valvuloplasty, open \\
\hline 4 & Mitral valve replacement & 2 & Ross procedure \\
\hline 4 & Pulmonary artery banding & 2 & Tetralogy of Fallot repair \\
\hline
\end{tabular}


TABLE E1. Continued

\begin{tabular}{|c|c|c|c|}
\hline $\begin{array}{c}\text { Highest } \\
\text { STAT category }\end{array}$ & Highest STAT procedure & $\begin{array}{c}\text { Index STAT } \\
\text { category }\end{array}$ & Index STAT procedure \\
\hline 4 & Pulmonary venous stenosis repair & 2 & Fontan operation \\
\hline 4 & Shunt, systemic to pulmonary & 2 & Aortic stenosis repair \\
\hline 4 & Shunt, systemic to pulmonary & 2 & Aortic valvuloplasty, open \\
\hline 4 & Shunt, systemic to pulmonary & 2 & Mitral valvuloplasty, open \\
\hline 4 & Aortic arch repair & 2 & Conduit placement (non-RV to PA) \\
\hline 4 & Aortic arch repair & 2 & Mitral stenosis repair \\
\hline 4 & Aortic arch repair & 2 & Pulmonary artery procedure \\
\hline 4 & Aortic arch repair & 2 & RVOT procedure \\
\hline 4 & Aortic arch repair & 2 & Tricuspid valvuloplasty, open \\
\hline 4 & Aortic arch repair & 2 & Truncal valve replacement \\
\hline 4 & Aortic dissection repair & 2 & Aortic root replacement \\
\hline 4 & Aortic dissection repair & 2 & Aortic valvuloplasty, open \\
\hline 4 & Aortic dissection repair & 2 & Fontan operation \\
\hline 4 & Aortic dissection repair & 2 & $\begin{array}{l}\text { Superior vena cava-pulmonary artery shunt (Glenn)/ } \\
\text { hemi-Fontan }\end{array}$ \\
\hline 4 & Aortic root replacement & 2 & $\begin{array}{l}\text { Anomalous aortic origin of coronary artery from } \\
\text { aorta repair }\end{array}$ \\
\hline 4 & Aortic root replacement & 2 & Aortic stenosis repair \\
\hline 4 & Arterial switch operation for TGA & 2 & Coarctation repair \\
\hline 4 & Atrial septal fenestration & 2 & Mitral stenosis repair \\
\hline 4 & Cardiac tumor resection & 2 & Mitral valvuloplasty, open \\
\hline 4 & Cardiac tumor resection & 2 & RVOT procedure \\
\hline 4 & Cardiac tumor resection & 2 & $\begin{array}{l}\text { Superior vena cava-pulmonary artery shunt (Glenn)/ } \\
\text { hemi-Fontan }\end{array}$ \\
\hline 4 & Common atrioventricular valve replacement & 2 & $\begin{array}{l}\text { Partial left ventriculectomy (LV reduction surgery) } \\
\text { Batista }\end{array}$ \\
\hline 4 & Common atrioventricular valve replacement & 2 & $\begin{array}{l}\text { Superior vena cava-pulmonary artery shunt (Glenn)/ } \\
\text { hemi-Fontan }\end{array}$ \\
\hline 4 & Ebstein's repair & 2 & RVOT procedure \\
\hline 4 & Ebstein's repair & 2 & Tricuspid valvuloplasty, open \\
\hline 4 & Heart transplant & 2 & Coarctation repair \\
\hline 4 & Heart transplant & 2 & Superior vena cava-pulmonary artery shunt (Glenn) \\
\hline 4 & Heart transplant & 2 & Tricuspid valvuloplasty, open \\
\hline 4 & Interrupted aortic arch repair & 2 & Aortic valvuloplasty, open \\
\hline 4 & Mitral valve replacement & 2 & Aortic stenosis repair \\
\hline 4 & Mitral valve replacement & 2 & Coarctation repair \\
\hline 4 & Pulmonary artery banding & 2 & $11 / 2$ Ventricular repair \\
\hline 4 & Pulmonary artery banding & 2 & AP window repair \\
\hline 4 & Pulmonary artery banding & 2 & Fontan operation \\
\hline 4 & Pulmonary venous stenosis repair & 2 & Aortic valvuloplasty, open \\
\hline 4 & Pulmonary venous stenosis repair & 2 & $\begin{array}{l}\text { Partial anomalous pulmonary venous connection } \\
\text { repair }\end{array}$ \\
\hline 4 & Pulmonary venous stenosis repair & 2 & Pulmonary artery procedure \\
\hline 4 & Ross-Konno procedure & 2 & Coarctation repair \\
\hline 4 & Ross-Konno procedure & 2 & Mitral stenosis repair \\
\hline
\end{tabular}


TABLE E1. Continued

\begin{tabular}{|c|c|c|c|}
\hline $\begin{array}{c}\text { Highest } \\
\text { STAT category }\end{array}$ & Highest STAT procedure & $\begin{array}{c}\text { Index STAT } \\
\text { category }\end{array}$ & Index STAT procedure \\
\hline 4 & Ross-Konno procedure & 2 & Pulmonary artery procedure \\
\hline 4 & Shunt, systemic to pulmonary & 2 & Mitral stenosis repair \\
\hline 4 & Shunt, systemic to pulmonary & 2 & Tricuspid valve replacement \\
\hline 4 & Unifocalization MAPCA (s) & 2 & Pulmonary artery procedure \\
\hline 4 & Pulmonary artery debanding & 1 & Ventricular septal defect repair \\
\hline 4 & Atrial septal defect creation (surgical) & 1 & Ventricular septal defect repair \\
\hline 4 & Pulmonary artery banding & 1 & Coarctation repair \\
\hline 4 & Atrial septal defect creation (surgical) & 1 & $\begin{array}{l}\text { Partial anomalous pulmonary venous connection } \\
\text { repair }\end{array}$ \\
\hline 4 & Aortic arch repair & 1 & Coarctation repair \\
\hline 4 & Aortic arch repair & 1 & Vascular ring/sling correction/division \\
\hline 4 & Atrial septal defect creation (surgical) & 1 & Tetralogy of Fallot repair \\
\hline 4 & Aortic arch repair & 1 & Ventricular septal defect repair \\
\hline 4 & Atrial septal defect creation (surgical) & 1 & Fontan operation \\
\hline 4 & Pulmonary venous stenosis repair & 1 & Atrial septal defect repair \\
\hline 4 & Pulmonary venous stenosis repair & 1 & Ventricular septal defect repair \\
\hline 4 & Atrial septal fenestration & 1 & Ventricular septal defect repair \\
\hline 4 & Common atrioventricular valvuloplasty & 1 & AV canal repair \\
\hline 4 & Pulmonary artery banding & 1 & Ventricular septal defect repair \\
\hline 4 & Aortic root replacement & 1 & Aortic valve replacement \\
\hline 4 & Aortic arch repair & 1 & Aortic valve replacement \\
\hline 4 & Common atrioventricular valvuloplasty & 1 & Partial AV canal repair (ostium primum ASD repair) \\
\hline 4 & Aortic arch repair & 1 & AV canal repair \\
\hline 4 & Atrial septal defect creation (surgical) & 1 & AV canal repair \\
\hline 4 & Common atrioventricular valvuloplasty & 1 & Fontan operation \\
\hline 4 & Pulmonary venous stenosis repair & 1 & Pulmonary valve replacement \\
\hline 4 & Shunt, systemic to pulmonary & 1 & $\begin{array}{l}\text { Partial anomalous pulmonary venous connection } \\
\text { repair }\end{array}$ \\
\hline 4 & Aortic dissection repair & 1 & Aortic valve replacement \\
\hline 4 & Atrial septal defect creation (surgical) & 1 & $\begin{array}{l}\text { Superior vena cava-pulmonary artery shunt (Glenn)/ } \\
\text { hemi-Fontan }\end{array}$ \\
\hline 4 & Mitral valve replacement & 1 & Aortic valve replacement \\
\hline 4 & Pulmonary venous stenosis repair & 1 & Fontan operation \\
\hline 4 & Pulmonary venous stenosis repair & 1 & Partial anomalous pulmonary venous repair \\
\hline 4 & Aortic arch repair & 1 & Partial AV canal repair (ostium primum ASD repair) \\
\hline 4 & Aortic arch repair & 1 & Superior vena cava-pulmonary artery shunt (Glenn) \\
\hline 4 & Atrial septal defect creation (surgical) & 1 & Aortic stenosis repair \\
\hline 4 & Atrial septal defect creation (surgical) & 1 & Superior vena cava-pulmonary artery shunt (Glenn) \\
\hline 4 & Cardiac tumor resection & 1 & Aortic valve replacement \\
\hline 4 & Cardiac tumor resection & 1 & Atrial septal defect repair \\
\hline 4 & Common atrioventricular valvuloplasty & 1 & Atrial septal defect repair \\
\hline 4 & Ebstein's repair & 1 & Atrial septal defect repair \\
\hline 4 & Heart transplant & 1 & Aortic valve replacement \\
\hline 4 & Heart transplant & 1 & Atrial septal defect repair \\
\hline
\end{tabular}


TABLE E1. Continued

\begin{tabular}{|c|c|c|c|}
\hline $\begin{array}{l}\text { Highest } \\
\text { STAT category }\end{array}$ & Highest STAT procedure & $\begin{array}{l}\text { Index STAT } \\
\text { category }\end{array}$ & Index STAT procedure \\
\hline 4 & Interrupted aortic arch repair & 1 & Coarctation repair \\
\hline 4 & Interrupted aortic arch repair & 1 & Ventricular septal defect repair \\
\hline 4 & Mitral valve replacement & 1 & AV canal repair \\
\hline 4 & Mitral valve replacement & 1 & Atrial septal defect repair \\
\hline 4 & Pulmonary venous stenosis repair & 1 & Aortic stenosis repair \\
\hline 4 & Pulmonary venous stenosis repair & 1 & Tetralogy of Fallot repair \\
\hline 4 & Shunt, systemic to pulmonary & 1 & Aortic stenosis repair \\
\hline 4 & $\begin{array}{l}\text { Total anomalous pulmonary venous connection } \\
\text { repair }\end{array}$ & 1 & AV canal repair \\
\hline 4 & $\begin{array}{l}\text { Total anomalous pulmonary venous connection } \\
\text { repair }\end{array}$ & 1 & Partial AV canal repair (ostium primum ASD repair) \\
\hline 4 & Unifocalization MAPCA (s) & 1 & Ventricular septal defect repair \\
\hline 4 & Unifocalization MAPCA (s) & 1 & Tetralogy of Fallot repair \\
\hline 3 & Atrial septal defect partial closure & 2 & Tetralogy of Fallot repair \\
\hline 3 & Shunt, ligation, and takedown & 2 & Fontan operation \\
\hline 3 & Shunt, ligation, and takedown & 2 & RVOT procedure \\
\hline 3 & Right ventricle-pulmonary artery conduit & 2 & Ross procedure \\
\hline 3 & Atrial septal defect partial closure & 2 & RVOT procedure \\
\hline 3 & Atrial septal defect partial closure & 2 & Tricuspid valvuloplasty, open \\
\hline 3 & Right ventricle-pulmonary artery conduit & 2 & Aortic root replacement \\
\hline 3 & Right ventricle-pulmonary artery conduit & 2 & Tricuspid valvuloplasty, open \\
\hline 3 & AV canal repair & 2 & Coarctation repair \\
\hline 3 & Atrial septal defect partial closure & 2 & Cor triatriatum repair \\
\hline 3 & Atrial septal defect partial closure & 2 & $\begin{array}{l}\text { Superior vena cava-pulmonary artery shunt (Glenn)/ } \\
\text { hemi-Fontan }\end{array}$ \\
\hline 3 & AV canal repair & 2 & Aortic valvuloplasty, open \\
\hline 3 & Atrial septal defect partial closure & 2 & Aortic stenosis repair \\
\hline 3 & Atrial septal defect partial closure & 2 & Mitral valvuloplasty, open \\
\hline 3 & Atrial septal defect partial closure & 2 & Ross procedure \\
\hline 3 & Fontan operation & 2 & Tricuspid valvuloplasty, open \\
\hline 3 & Pulmonary embolectomy & 2 & Tricuspid valvuloplasty, open \\
\hline 3 & Right ventricle-pulmonary artery conduit & 2 & Mitral valvuloplasty, open \\
\hline 3 & Right ventricle-pulmonary artery conduit & 2 & Pacemaker insertion/revision \\
\hline 3 & Right ventricle-pulmonary artery conduit & 2 & Pulmonary valvuloplasty, open \\
\hline 3 & Right ventricle-pulmonary artery conduit & 2 & Ventricular septal defect repair \\
\hline 3 & Truncal valvuloplasty & 2 & Pulmonary artery procedure \\
\hline 3 & Truncal valvuloplasty & 2 & RVOT procedure \\
\hline 3 & Atrial septal defect partial closure & 1 & Ventricular septal defect repair \\
\hline 3 & Shunt, ligation, and takedown & 1 & Tetralogy of Fallot repair \\
\hline 3 & Shunt, ligation, and takedown & 1 & Ventricular septal defect repair \\
\hline 3 & Atrial septal defect partial closure & 1 & Tetralogy of Fallot repair \\
\hline 3 & Right ventricle-pulmonary artery conduit & 1 & Ventricular septal defect repair \\
\hline 3 & Right ventricle-pulmonary Artery conduit & 1 & Pulmonary valve replacement \\
\hline 3 & Aneurysm repair & 1 & Pulmonary valve replacement \\
\hline
\end{tabular}


TABLE E1. Continued

\begin{tabular}{|c|c|c|c|}
\hline $\begin{array}{l}\text { Highest } \\
\text { STAT category }\end{array}$ & Highest STAT procedure & $\begin{array}{l}\text { Index STAT } \\
\text { category }\end{array}$ & Index STAT procedure \\
\hline 3 & Atrial septal defect partial closure & 1 & Pulmonary valve replacement \\
\hline 3 & Right ventricle-pulmonary artery conduit & 1 & Aortic valve replacement \\
\hline 3 & Shunt, ligation, and takedown & 1 & Fontan operation \\
\hline 3 & Shunt, ligation, and takedown & 1 & $\begin{array}{l}\text { Superior vena cava-pulmonary artery shunt (Glenn)/ } \\
\text { hemi-Fontan }\end{array}$ \\
\hline 3 & Tricuspid valve replacement & 1 & Pulmonary valve replacement \\
\hline 3 & Tricuspid valve replacement & 1 & Ventricular septal defect repair \\
\hline 3 & AV canal repair & 1 & Atrial septal defect repair \\
\hline 3 & Aneurysm repair & 1 & Tetralogy of Fallot repair \\
\hline 3 & Ventricular septal fenestration & 1 & Tetralogy of Fallot repair \\
\hline 3 & Konno procedure & 1 & Aortic stenosis repair \\
\hline 3 & Konno procedure & 1 & Conduit reoperation \\
\hline 3 & Konno procedure & 1 & Ventricular septal defect repair \\
\hline 2 & Tricuspid valvuloplasty, open & 1 & Ventricular septal defect repair \\
\hline 2 & RVOT procedure & 1 & Ventricular septal defect repair \\
\hline 2 & Pulmonary valvuloplasty, open & 1 & Ventricular septal defect repair \\
\hline 2 & Pulmonary valvuloplasty, open & 1 & Tetralogy of Fallot repair \\
\hline 2 & Mitral valvuloplasty, open & 1 & Ventricular septal defect repair \\
\hline 2 & RVOT procedure & 1 & Tetralogy of Fallot repair \\
\hline 2 & Mitral valvuloplasty, open & 1 & AV canal repair \\
\hline 2 & Mitral valvuloplasty, open & 1 & Atrial septal defect repair \\
\hline 2 & Aortic valvuloplasty, open & 1 & Ventricular septal defect repair \\
\hline 2 & Mitral valvuloplasty, open & 1 & Aortic stenosis repair \\
\hline 2 & Tricuspid valvuloplasty, open & 1 & Atrial septal defect repair \\
\hline 2 & Tricuspid valvuloplasty, open & 1 & Tetralogy of Fallot repair \\
\hline 2 & RVOT procedure & 1 & Conduit reoperation \\
\hline 2 & Tricuspid valvuloplasty, open & 1 & Aortic stenosis repair \\
\hline 2 & Tricuspid valvuloplasty, open & 1 & AV canal repair \\
\hline 2 & Tricuspid valvuloplasty, open & 1 & Fontan operation \\
\hline 2 & Aortic root replacement & 1 & Aortic valve replacement \\
\hline 2 & Tricuspid valve replacement & 1 & Pulmonary valve replacement \\
\hline 2 & Tricuspid valve replacement & 1 & Ventricular septal defect repair \\
\hline 2 & Tricuspid valvuloplasty, open & 1 & Partial AV canal repair (ostium primum ASD repair) \\
\hline 2 & Aortic valvuloplasty, open & 1 & Partial AV canal repair (ostium primum ASD repair) \\
\hline 2 & Aortic valvuloplasty, open & 1 & Atrial septal defect repair \\
\hline 2 & Aortopexy & 1 & Conduit reoperation \\
\hline 2 & Aortic valvuloplasty, open & 1 & AV canal repair \\
\hline 2 & Aortopexy & 1 & Tetralogy of Fallot repair \\
\hline 2 & Aortopexy & 1 & Ventricular septal defect repair \\
\hline 2 & LV to aorta tunnel repair & 1 & Aortic stenosis repair \\
\hline 2 & Mitral valvuloplasty, open & 1 & Coarctation repair \\
\hline 2 & Pulmonary valvuloplasty, open & 1 & AV canal repair \\
\hline 2 & Pulmonary valvuloplasty, open & 1 & Aortic stenosis repair \\
\hline 2 & Aortic root replacement & 1 & Conduit reoperation \\
\hline
\end{tabular}


TABLE E1. Continued

\begin{tabular}{llcl}
\hline $\begin{array}{c}\text { Highest } \\
\text { STAT category }\end{array}$ & \multicolumn{1}{c}{ Highest STAT procedure } & $\begin{array}{c}\text { Index STAT } \\
\text { category }\end{array}$ & \multicolumn{1}{c}{ Index STAT procedure } \\
\hline 2 & Aortic root replacement & 1 & \multicolumn{1}{c}{ Pulmonary valve replacement } \\
\hline 2 & Aortic stenosis repair & 1 & Coarctation repair \\
\hline 2 & Aortic valvuloplasty, open & 1 & Aortic valve replacement \\
2 & Aortopexy & 1 & Aortic stenosis repair \\
\hline 2 & Aortopexy & 1 & Aortic valve replacement \\
2 & LV to aorta tunnel repair & 1 & AV canal repair \\
\hline 2 & LV to aorta tunnel repair & 1 & Aortic valve replacement \\
\hline 2 & Partial left ventriculectomy (LV reduction surgery) & 1 & Aortic stenosis repair \\
\hline 2 & Batista & 1 & Aortic valve replacement \\
\hline 2 & Partial left ventriculectomy (LV reduction surgery) & & AV canal repair \\
\hline
\end{tabular}

STAT, Society of Thoracic Surgeons-European Association for Cardio-Thoracic Surgery; RPA, right pulmonary artery; LPA, left pulmonary artery; AV, atrioventricular; $T G A$, transposition of great artery; MAPCA, multiple aortopulmonary collateral; VSD, venticular septal defect; $P A$, pulmonary artery; RVOT, right ventricular outflow tract; $A P$, aortopulmonary; $L V$, left ventricle; $A S D$, atrial septal defect. 
TABLE E2. Observed and predicted mortality among patients at a participating center by classifying the patients using 2 classification systems

\begin{tabular}{|c|c|c|c|c|c|c|c|c|}
\hline \multirow[b]{2}{*}{ All patients } & \multicolumn{4}{|c|}{ Index operation } & \multicolumn{4}{|c|}{ Highest complexity operation } \\
\hline & $\mathbf{N}$ & Observed & Expected & $\mathbf{O} / \mathbf{E}$ & $\mathbf{n}$ & Observed & Expected & $\mathbf{O} / \mathbf{E}$ \\
\hline STAT category 1 & 530 & $5(0.9)$ & 4.1 & 1.21 & 203 & $1(0.5)$ & 1.2 & 0.83 \\
\hline STAT category 2 & 471 & $11(2.3)$ & 10.2 & 1.07 & 449 & $7(1.5)$ & 7.3 & 0.95 \\
\hline STAT category 3 & 164 & $5(3.0)$ & 4.7 & 1.05 & 364 & $10(2.7)$ & 10.4 & 0.96 \\
\hline STAT category 4 & 380 & $14(3.7)$ & 14.7 & 0.94 & 526 & $17(3.2)$ & 17.7 & 0.96 \\
\hline STAT category 5 & 53 & $7(13.2)$ & 6.6 & 1.05 & 56 & $7(12.5)$ & 6.1 & 1.14 \\
\hline
\end{tabular}

Values are presented as $\mathrm{n}$ or $\mathrm{n}(\%)$. O/E, Observed-to-expected rate; STAT, Society of Thoracic Surgeons-European Association for Cardio-Thoracic Surgery. 